\title{
Catastrophic health expenditure: a comparative study between hypertensive patients with and without complication in rural Shandong, China
}

Xinyi Zhang ${ }^{1+}$, Qiongqiong Xu ${ }^{1+}$, Xiaolei Guo ${ }^{2}$, Zhengyue Jing ${ }^{1}$, Long Sun ${ }^{1}$, Jiajia Li $^{1}$ and Chengchao Zhou ${ }^{1,3^{*}}$

\begin{abstract}
Background: Some previous studies have assessed catastrophic health expenditure (CHE) in households with hypertensive patients, but few have examined the difference of CHE in hypertensive patients with and without complications. The purpose of this study is to compare the incidence and determinants of CHE between hypertensive patients with and without complications.
\end{abstract}

Methods: Data of this study were from a cross-sectional study in Shandong Province in China in 2016. Of the recruited 3457 hypertensive patients registered in the NCDs management system in the sampling villages, 3113 completed the survey, with a response rate of $90.05 \%$.CHE was defined as out-of-pocket payments for hypertensive care that equaled or exceeded $40 \%$ of the household capacity to pay (non-food expenditure). Hypertension complications (e.g., stroke, coronary heart disease, hypertensive kidney disease, etc.) were collected in this study, which was categorized into 0 (no), 1(single), and 2 and more according to the types of hypertensive complications. We employed Chi-square test to explore associated factors and logistic regression model to identify the determinants of CHE.

Results: The incidence of CHE and impoverishment is 13.6 and 10.8\% among hypertensive patients. The incidence of CHE with one complication is $25.3 \%(P=0.000, \mathrm{OR}=2.29)$ and $47.3 \%(P=0.000, \mathrm{OR}=3.60)$ in patients with two or more complications, which are both statistically higher than that in patients without complication (6.1\%). Across all types of patients, income levels are inversely related to the incidence of CHE. Patients who use outpatient or inpatient service are more likely to experience CHE $(P=0.000)$. Factors including living arrangements, family size, educational attainment are found to be significantly associated with CHE in some subgroups $(P<0.05)$.

Conclusions: $\mathrm{CHE}$ and impoverishment incidence among hypertensive patients are both high in rural China. Patients with hypertensive complication are at higher catastrophic risk than those without complication. More attention needs to be paid to households with hypertension patients, especially for those with hypertension complications.

Keywords: Catastrophic health expenditure, Hypertension, Complication, Determinants, China

\footnotetext{
* Correspondence: zhouchengchao@sdu.edu.cn

${ }^{+}$Xinyi Zhang and Qiongqiong Xu contribute equally, and are co-first authors

of this manuscript.

'School of Public Health, Shandong University, Jinan 250012, China

${ }^{3} \mathrm{NHC}$ Key Lab of Health Econonics and Policy Research, Shandong University, Jinan 250012, China

Full list of author information is available at the end of the article
}

(c) The Author(s). 2020 Open Access This article is licensed under a Creative Commons Attribution 4.0 International License, which permits use, sharing, adaptation, distribution and reproduction in any medium or format, as long as you give appropriate credit to the original author(s) and the source, provide a link to the Creative Commons licence, and indicate if changes were made. The images or other third party material in this article are included in the article's Creative Commons licence, unless indicated otherwise in a credit line to the material. If material is not included in the article's Creative Commons licence and your intended use is not permitted by statutory regulation or exceeds the permitted use, you will need to obtain permission directly from the copyright holder. To view a copy of this licence, visit http://creativecommons.org/licenses/by/4.0/ The Creative Commons Public Domain Dedication waiver (http://creativecommons.org/publicdomain/zero/1.0/) applies to the data made available in this article, unless otherwise stated in a credit line to the data. 


\section{Background}

Cardiovascular disease is the world's leading cause of deaths, accounting for one third of the total [1]. Hypertension is one of the major risk factors for cardiovascular disease, which plays a major role in the development of cerebrovascular disease, cardiac and renal failure [2]. About $50 \%$ of coronary heart disease and $75 \%$ of the burden of cerebrovascular disease are caused by hypertension [3]. Globally, approximately one billion people suffer from hypertension. It is estimated that the incidence of hypertension will rise from 26.4 to $29.2 \%$ in the world by 2025 [2, 4]. Hypertension and its complications are the leading causes of death and disability [5]. The number of deaths worldwide due to hypertensive complication is 9.4 million, of which $45 \%$ die from heart disease, and 51\% die from stroke [6]. The World Health Organization (WHO) ranks hypertension as one of the top five health risk factors [5].

In China, the prevalence of hypertension in adults aged 18 years and older was $27.9 \%$, with more than 250 million patients, and the number of new cases per year about 10 million. This prevalence was even higher (32.5\%) among the adults aged 35 to 74 [7-9]. It was estimated that 2.5 million Chinese adults died from hypertension and its complications, accounting for $28 \%$ of all deaths in 2013 [10]. China's total health expenditure was US\$ 30.57 billion in 2013, of which the direct economic burden of hypertension accounted for $6.61 \%$ [11] . Chinese Health Statistics estimated that the out of pocket (OOP) expenditure of residents was US\$ 16.39 billion in 2014, which means OOP that payments remain relatively high in China [12]. Previous studies also showed that households with a large proportion of OOP expenses were extremely vulnerable to financial difficulties, especially those with chronic diseases [13]. In the past decades, the Chinese government has introduced several social health insurance schemes (i.e., Basic Medical Insurance Scheme for Urban Employees, Medical Insurance for urban and rural residents) to the urban and rural residents, and also medical financial assistance to the poor, so as to reduce economic burden of the households with patients [14] . However, the households which experiencing hypertension and hypertension complications (i.e., heart attack, stroke and kidney failure) often spend a substantial share of their income on hypertension-related healthcare use [4]. Previous study in China showed that hypertension and its complications ranked the first of all diseases with heavy economic burden among the rural residents [15]. In addition, rural residents are found to be of higher economic risk than urban residents $[16,17]$. For rural households in China, the emergence of such diseases might lead to severe economic risks and a further induced poverty [18]. The fundamental role of a healthcare system is not only to facilitate access to health services when needed, but also protect households from financial catastrophe associated with illness [19] .

However, many people still do not have access to the healthcare services they needed owing to economic conditions [20]. When healthcare expenditure seriously affects household living conditions, or even push the household into poverty, we call it "catastrophic" [21], which can be quantified by catastrophic health expenditure (CHE). Generally, we define CHE as out-of-pocket payment (OOP) for health care that exceed a specified proportion of household income, with the consequence that the household may sacrifice the consumption of other goods or services necessary for their well-being $[21,22]$. In China, several studies have explored the $\mathrm{CHE}$ among the general populations. A study using a national representative data by $\mathrm{Li}$ et al. found that the incidence of $\mathrm{CHE}$ among the general population in China was $13.0 \%$, which was higher than that in some other low-income countries [23]. Households with members suffering from chronic diseases have a greater possibility of experiencing catastrophic health expenditure than their counterparts, which is consistent in both developed countries and developing countries [23, 24]. Under a rapid increasing trend in prevalence of hypertension, to identify the incidence and determinants of CHE for hypertension patients in rural areas, and evaluate the effect of hypertension complications on the incidence, intensity of $\mathrm{CHE}$ are of high priority for protecting households with hypertension from financial catastrophe in rural China.

To date, there are only very few studies have explored the CHE in hypertensive patients, and no studies have assessed the effect of complications on the incidence, intensity of $\mathrm{CHE}$ in China. The overall objective of this study is to compare CHE between hypertensive patients with and without complications. To do so, we have several specific objectives. Firstly, we would compare $\mathrm{CHE}$ between hypertensive patients with complications and without complications. Secondly, we will identify the determinants for $\mathrm{CHE}$ in the hypertensive patients in rural China. Like China, growing incidence of hypertension and co-payment for its health expenditure are also issues in other low and middle income countries (LMICs), the findings from this study is also of high significance to other LMICs.

\section{Methods}

\section{Study participants}

Data for the current analysis came from a crosssectional survey our research team conducted in Shandong Province, which was the second largest province in China. The prevalence of hypertension in Shandong residents aged 18-69 in 2013 was 27.9\%, significantly higher 
than the national average level [25]. An expected incidence of $10 \%$ of CHE and also a tolerance error of 0.15 were used to estimate the sample size, and at least 1600 hypertensive patients should be investigated. A 3-stage cluster sampling was employed to select participants in this survey. Firstly, according to Gross Domestic Product (GDP) per capita in Shandong in 2015, we stratified all counties into three groups. We selected four counties as the study sites, one (Rushan) from the upper level, two (Yiyuan and Gaotang) from the medium level, and one (Liangshan) from the lower level. Secondly, likewise, we stratified all townships into three groups in each selected county, from each group we chose one township. Thirdly, we then randomly chose two villages with a size of permanent residents over 1000 from each selected township. More details about data collection methods were described in our previous studies [26].

According to the Chinese guideline for the management of hypertension, the criterion for hypertension was systolic blood pressure (SBP) $\geq 140$ mm HG (1 mm HG = $0.133 \mathrm{kPa}$ ) and diastolic blood pressure (DBP) $\geq 90 \mathrm{~mm}$ HG [27]. In this study, the status of hypertension and also its complications were diagnosed by medical professionals and registered in the sample village chronic case management system. We have collected the hypertension status and its complications of the participants from the chronic case management system in the sampling villages. In order to validate the information, we asked the respondents about whether they were diagnosed with hypertension complications and further for specific complications again when conducting face-to-face interview. All of the 3457 hypertensive patients under NCDs case management in the sampling communities or villages were recruited in this survey. In total, 3113 rural hypertensive patients complete the interview and were included in current study, with a response rate of $90.05 \%$.

\section{Data collection}

All the subjects were interviewed face-to-face using a standard structured questionnaire by trained postgraduate students from Shandong University School of Public Health. The questionnaire used in this study has been published elsewhere [28]. In order to ensure a high response rate, about 1 week before the normal survey, the sampling hypertensive patients were informed of the purpose and time of the interview by the local healthcare practitioners, and signed the willingness for the participation in the survey. To achieve the purposes of this study, completed questionnaires were subject to stringent quality assurance in each day. The questionnaire included the patients' basic information (gender, age, marital status, education attainment, household composition), household income, total household expenditure, food expenditure, OOP payments for hypertensionrelated healthcare, health insurance status, and outpatient service and in-patient service. When conducting the interview, the main information of the interviewed hypertensive patients in the case management system would be also reviewed by the interviewers to validate the response of the interviewees.

\section{Variables and definitions}

\section{Outcome and measurement}

In our study, we define CHE as OOP (out-of-pocket healthcare payments) that equal or exceed $40 \%$ of the household capacity to pay [29], of which, the household capacity to pay means that household total expenditure minus food expenditure $[30,31]$. OOP expense for hypertension and its complications refers to the direct expenses paid to the medical service provider of the whole household, excluding indirect costs such as loss of working time, transportation and accommodation fees incurred at the time of medical treatment [32, 33]. We usually use incidence and intensity indicators to assess CHE [34, 35]. The incidence of CHE can be expressed by head count $(\mathrm{HC})$ and intensity indicators can be evaluated by mean gap (MG) and mean positive gap (MPG). $\mathrm{HC}$ is estimated as follows:

$$
H C=\frac{1}{N} \sum_{i=1}^{N} E
$$

Where $\mathrm{N}$ is the sample size, $\mathrm{E}$ is an indicator equal to 1 if OOP of a household $i$ as a proportion of its capacity to pay is greater than the threshold $\mathrm{Z}$ and zero otherwise. MG is the average amount by which payments, as a proportion of income, equals or exceeds $40 \%$ of their capacity to pay. It is estimated as follows:

$$
M G=\frac{1}{N} \sum_{i=1}^{N} G
$$

Where $\mathrm{N}$ is the sample size, $\mathrm{G}$ is an indication of how much OOP exceed the threshold, equal to $\mathrm{Ti} / \mathrm{Xi}-\mathrm{Z}$ if $\mathrm{Ti} / \mathrm{X}>\mathrm{Z}$ and zero otherwise. Here, Ti is the OOP payments of household $\mathrm{i}, \mathrm{Xi}$ is the household capacity to pay and $\mathrm{Z}$ is the threshold share. MPG is defined as the head count being a fraction of the MG. In addition, the impoverishment effect due to hypertension-related OOP payment is also assessed in this study, which is measured by the difference between the relevant pre-payment and post-payment measures. The specific calculating methods of CHE incidence and intensity, impoverishment incidence are described in detail by Wagstaff and colleagues elsewhere [22]. 
Independent vairables and covariates

Hypertensive complication

A question of "Have you ever been diagnosed with hypertension complication (including stroke, coronary heart disease, hypertensive kidney disease, heart disease etc.)?" was used to measure hypertension complication in this study. If the answer was 'yes', we will record the specific disease(s) in details. We categorized the types of hypertensive complications into 0 (no), 1(single), and 2(multiple complications).

\section{Hypertension-related variables}

Hypertension-related variables included duration of hypertension ( $\leqq 5,5-, 10-,>15$ years), hospitalization due to hypertension and its complication in the past year (yes vs. no), and out-patient service (yes vs. no).

\section{Social demographic characteristics}

The social demographic characteristics of the participants included age, gender, marital status, educational attainment, health insurance status, head of household, gender of household head, family size, and household living arrangements.

\section{Economic status}

Economic status included household income (Q1, Q2, Q3, Q4, and Q1 was the poorest, and Q4 was the richest), Dibao (yes vs. no), debt (yes vs. no). We used a question of "How much was the total income of your household in the past year (urban households were disposable income, rural households were net income)?" to measure the yearly household income.

\section{Data analysis}

The data is double entered and checked using EPI Data 3.1. The statistical package SPSS 22.0 is used to analyze the data. Household total expenditure, food expenditure, capacity to pay and OOP payments are presented as means and medians. Logistic regression analysis is used to compare the incidence of CHE between hypertensive patients with and without complications, Chi-square test is used to explore which factors are associated with CHE. Multivariate logistic regression analysis is employed to assess the determinants for $\mathrm{CHE}$ in each type of subgroups. Statistical significance is set at the $5 \%$ level. Sampling weights were included in all analyses to deal with potential cluster effects.

\section{Results}

\section{Demographic characteristics}

We present the descriptive statistics of the study participants in Table 1. Of the 3113 hypertensive patients, 2009(64.5\%) have no complication, 1013(32.5\%) have one complication, and $91(3 \%)$ have two or more complications. Majority of the study participants are women (63.3\%), with an education level of elementary school and below (78.7\%). As for the living arrangements, empty-nest couples account for $65.2 \%$, while empty-nest single account for $14.1 \%$. During the 12 months prior to survey, 414(13.3\%) patients used in-patient service, 410(13.2) patients used out-patient service. CHE was different across different types of economic status $(P<0.001)$, number of complications $(P<0.001)$, education level $(P<0.05)$, duration of disease $(P<0.01)$, inpatient service $(P<0.001)$, outpatient service $(P<0.001)$, living arrangement $(P<0.05)$.

Patients' household income/expenditure, capacity to pay and OOP payments for hypertension

The mean annual household income is US\$2260 (a currency exchange rate of Chinese RMB 689 Yuan to US $\$ 100$ dollar, the same below), with a highest mean income of US\$2427 in patients with no complication, and a lowest mean income of US\$1451 in hypertensive patients with two or more complications. Mean annual household expenditure is US\$2487(with a median of US\$1836), and the mean household food expenditure is US\$720(median value US\$610). Mean OOP payment for hypertension-related healthcare is US $\$ 272$ (with a median of US\$53), which accounts for $15.4 \%$ of the mean household capacity to pay, and $12.1 \%$ of the mean household income. Hypertensive patients with two or more complications have highest share of household income (78.1\%) and capacity to pay (53.6\%), while patients with no complication have the lowest share of household income (4.3\%) and capacity to pay (6.2\%) (See the Table 2 ).

\section{Incidence of CHE and impoverishment among patients with different numbers of complications}

Figure 1 presents the incidence of $\mathrm{CHE}$ and impoverishment effect for different types of patients, of which the overall incidence of CHE and impoverishment are 13.6 and $10.8 \%$ respectively. Specifically, $\mathrm{CHE}$ incidence is highest among the hypertensive patients with two or more complications (47.3\%), and is lowest among the patients with no complication (6.1\%). Similarly, the incidence of impoverishment is highest among the hypertensive patients with two or more complications (31.9\%), and is lowest among the patients with no complication (5.4\%).

\section{CHE for hypertensive patients with different numbers of complications}

In Table 3, we can observe an inverse association between CHE incidence and household income. Over 21\% of patients in the poorest quartile (Q1) compared to $6.9 \%$ of those in the richest households (Q4). Similar trends are observed among all of three types of 
Table 1 Socio-demographic characteristics of study participants in rural Shandong, China, 2016

\begin{tabular}{|c|c|c|c|}
\hline Characteristics & $N(\%)$ & OR & $95 \% \mathrm{Cl}$ \\
\hline Observations & $3113(100)$ & - & - \\
\hline \multicolumn{4}{|l|}{ Age (years) } \\
\hline$\leq 45$ & $60(1.90)$ & 1.0 & \\
\hline $45-60$ & $787(25.3)$ & 3.01 & $0.72-12.57$ \\
\hline $60-70$ & $1338(43.0)$ & 4.42 & $1.07-18.25^{*}$ \\
\hline$>70$ & $928(29.8)$ & 6.46 & $1.56-26.70^{*}$ \\
\hline \multicolumn{4}{|l|}{ Gender } \\
\hline Male & $1142(36.7)$ & 1.0 & \\
\hline Female & $1971(63.3)$ & 1.17 & $0.94-1.45$ \\
\hline \multicolumn{4}{|l|}{ Marital status } \\
\hline Single & $64(2.1)$ & 1.0 & \\
\hline Married & $2571(82.6)$ & 1.98 & $0.72-5.49$ \\
\hline Bereft of spouse $^{a}$ & $478(15.4)$ & 4.92 & $1.75-13.82^{* *}$ \\
\hline \multicolumn{4}{|l|}{ Complications } \\
\hline 0 & $2009(64.5)$ & 1.0 & \\
\hline 1 & $1013(32.5)$ & 5.18 & $4.12-6.53^{* * *}$ \\
\hline$\geq 2$ & $91(3.0)$ & 13.736 & $8.76-21.55^{* * *}$ \\
\hline \multicolumn{4}{|l|}{ Education } \\
\hline None & $1391(44.7)$ & 1.0 & \\
\hline Primary school & $1057(34.0)$ & 0.61 & $0.48-0.76^{* * *}$ \\
\hline Junior school & $517(16.6)$ & 0.49 & $0.35-0.68^{* * *}$ \\
\hline Senior school or above & $148(4.8)$ & 0.58 & $0.34-0.99^{*}$ \\
\hline \multicolumn{4}{|l|}{ Household income } \\
\hline $\mathrm{Q}^{\mathrm{b}}$ & $755(24.2)$ & 1.0 & \\
\hline Q1 & $783(25.2)$ & 3.75 & $2.69-5.21^{* * *}$ \\
\hline Q2 & $774(24.9)$ & 2.17 & $1.53-3.07^{* * *}$ \\
\hline Q3 & $801(25.7)$ & 1.78 & $1.24-2.53^{*}$ \\
\hline \multicolumn{4}{|l|}{ Health insurance ${ }^{c}$} \\
\hline URBMI & $2983(95.8)$ & 1.0 & \\
\hline UEBMI & $40(1.3)$ & 0.33 & $0.08-1.36$ \\
\hline $\mathrm{CMl}$ & $11(0.4)$ & 0.62 & $0.08-4.87$ \\
\hline Others $^{d}$ & $79(2.5)$ & 0.51 & $0.22-1.18$ \\
\hline \multicolumn{4}{|l|}{ Duration of disease (years) } \\
\hline$\leq 5$ & $1031(33.1)$ & 1.0 & \\
\hline $5-10$ & $1050(33.7)$ & 1.26 & $0.96-1.65$ \\
\hline $10-15$ & $397(12.8)$ & 1.74 & $1.25-2.41^{* *}$ \\
\hline$>15$ & $635(20.4)$ & 1.83 & $1.38-2.43^{* * *}$ \\
\hline \multicolumn{4}{|l|}{ In-Patient } \\
\hline No & $2699(86.7)$ & 1.0 & \\
\hline Yes & $414(13.3)$ & 16.58 & $12.99-21.14^{* * *}$ \\
\hline \multicolumn{4}{|l|}{ Out-Patient } \\
\hline No & $2703(86.8)$ & 1.0 & \\
\hline Yes & $410(13.2)$ & 3.29 & $2.58-4.20^{* * *}$ \\
\hline
\end{tabular}


Table 1 Socio-demographic characteristics of study participants in rural Shandong, China, 2016 (Continued)

\begin{tabular}{|c|c|c|c|}
\hline Characteristics & N (\%) & OR & $95 \% \mathrm{Cl}$ \\
\hline \multicolumn{4}{|l|}{$\overline{\text { Dibao }}^{e}$} \\
\hline No & $2943(94.5)$ & 1.0 & \\
\hline Yes & $170(5.5)$ & 2.29 & $1.59-3.29^{* * *}$ \\
\hline \multicolumn{4}{|l|}{ Be in debt } \\
\hline No & $2707(87.0)$ & 1.0 & \\
\hline Yes & $406(13.0)$ & 0.99 & $0.66-1.24$ \\
\hline \multicolumn{4}{|l|}{ Head of household } \\
\hline No & $1424(45.7)$ & 1.0 & \\
\hline Yes & $1689(54.3)$ & 1.31 & $1.06-1.61^{*}$ \\
\hline \multicolumn{4}{|c|}{ Head of household's gender } \\
\hline Male & $2415(77.6)$ & 1.0 & \\
\hline Female & $698(22.4)$ & 1.71 & $1.36-2.14^{*}$ \\
\hline \multicolumn{4}{|l|}{ Family size } \\
\hline$\leq 4$ & $2858(91.8)$ & 1.0 & \\
\hline$>4$ & $255(8.2)$ & 0.41 & $0.24-0.68^{* *}$ \\
\hline \multicolumn{4}{|l|}{ Living arrangement } \\
\hline Others & $642(20.6)$ & 1.0 & \\
\hline Empty-nest single & $440(14.1)$ & 4.32 & $2.99-6.24^{* * *}$ \\
\hline Empty-nest couple & $2031(65.2)$ & 1.88 & $1.36-2.60^{* * *}$ \\
\hline
\end{tabular}

a divorced participants are categorized into the group "Bereft of spouse"

${ }^{\mathrm{b}}$ Quartile $1(\mathrm{Q} 1)$ is the poorest and Quartile $4(\mathrm{Q} 4)$ is the richest

c URBMI Urban Residents Basic Medical Insurance, UEBMI Urban Employees Basic Medical Insurance, CMI Commercial Medical Insurance

d 40 uninsured patients are categorized into the group "others"

e "Dibao" means low-income households in China, which living and medical aids from municipal governments and other welfare programs

*** $P<0.001,{ }^{* *} P<0.01, * P<0.05$

hypertensive patients. In each income level, $\mathrm{CHE}$ incidence is highest in the patients with two or more complications.

In addition, we also use the overshoot and mean positive overshoot indicators to describe the intensity of catastrophic health expenditure. With the increase of income level, the overshoot and mean positive overshoot of CHE gradually decrease, showing a negative correlation trend. On average, health care payments for hypertension are $8.3 \%$ higher than the $40 \%$ threshold. For those experienced $\mathrm{CHE}$, the MPO was found to increase to $61 \%$.

\section{CHE distribution}

For hypertensive patients, out-patient (13.2\%) and inpatient (13.3\%) are at high risk of experiencing CHE, no matter whether there is complication or not. Among the patients with no or only one kind of complication, those who are older, who with lower household income, and those with less than four family members are more likely to experience CHE. We also find that in patients with two or more complications, female and patients with lower education are inclined to suffer CHE (Table 4).

\section{Determinants of CHE in patients with different numbers of complications}

For better understanding of the determinants of CHE in each subgroup, we use a logistic regression model to examine the related factors of CHE for each of the three subgroups separately in Table 5. Two factors are found to be statistically significant $(P<0.05)$ in all three types of patients, including outpatient service use in the past 6 months, and inpatient service use in the 12 months. Among the patients with no complication, those emptynest singles and with lower education level are more likely to experience CHE $(\mathrm{P}<0.05)$. Likewise, those who have lower household income are more likely to experience CHE in patients with one complication $(\mathrm{P}<0.05)$.

\section{Discussion}

The participants in this study were selected from the chronic patients' management system in the sampling villages, which were randomly chosen from those selected counties based on GDP per capita. This sampling process enables its representativeness of the rural Shandong, China. This survey based on villages offers an insight into the economic burden shouldered by the 
Table 2 Distribution of capacity to pay and OOP costs for health care across hypertensive patients in rural Shandong, China, 2016

\begin{tabular}{|c|c|c|c|c|}
\hline Indicators & One complication & Two or more complications & No complication & Total \\
\hline Frequency & 1013 & 91 & 2009 & 3113 \\
\hline \multicolumn{5}{|l|}{ Average OOP ${ }^{a}$ cost of health care (US\$) ${ }^{b}$} \\
\hline Mean & 529 & 1133 & 103 & 272 \\
\hline Median & 196 & 609 & 29 & 53 \\
\hline \multicolumn{5}{|l|}{ Average annual household income } \\
\hline Mean & 2000 & 1451 & 2427 & 2260 \\
\hline Median & 1065 & 871 & 1306 & 1164 \\
\hline \multicolumn{5}{|l|}{ Average annual household expenditure } \\
\hline Mean & 2622 & 2722 & 2048 & 2487 \\
\hline Median & 2003 & 2220 & 1741 & 1836 \\
\hline \multicolumn{5}{|l|}{ Average annual household food expenditure } \\
\hline Mean & 706 & 610 & 732 & 720 \\
\hline Median & 610 & 610 & 610 & 610 \\
\hline \multicolumn{5}{|l|}{ Average capacity to pay ${ }^{c}$} \\
\hline Mean & 1916 & 2112 & 1676 & 1767 \\
\hline Median & 1338 & 1512 & 1074 & 1161 \\
\hline OOP costs share of household income(\%) & 26.4 & 78.1 & 4.3 & 12.1 \\
\hline OOP costs share of capacity to pay(\%) & 27.6 & 53.6 & 6.2 & 15.4 \\
\hline
\end{tabular}

US\$ United States dollar

a OOP out-of-pocket

${ }^{\mathrm{b}}$ A currency exchange rate of Chinese RMB 689 Yuan to US\$100 dollar

c Capacity to pay means that household expenditure minus food expenditure

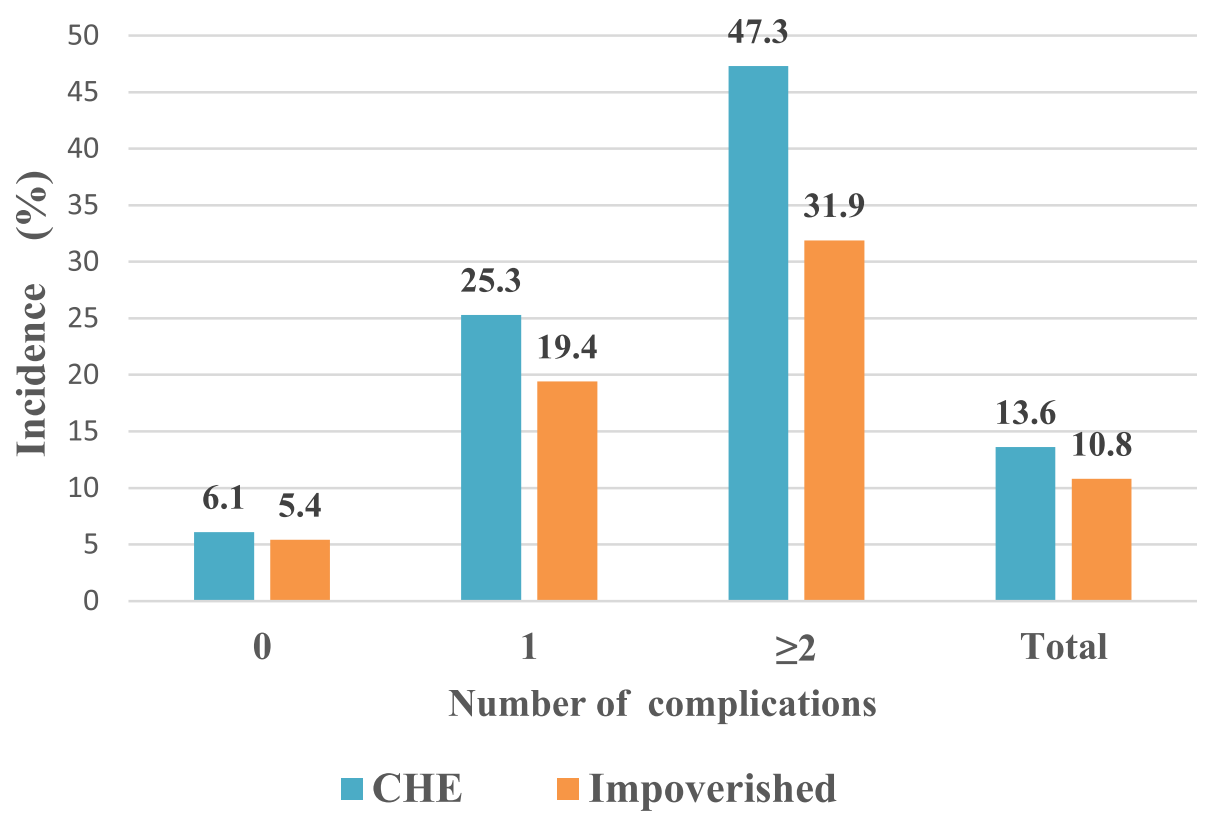

Fig. 1 Incidence of the CHE and impoverishment for hypertensive patients in rural Shandong, China, 201 
Table 3 Incidence and intensity of catastrophic health expenditure by economic status and patient composition in rural Shandong, China, 2016

\begin{tabular}{|c|c|c|c|c|}
\hline $\mathrm{CHE}$ & No complication & One complication & Two or more complications & Total \\
\hline \multicolumn{5}{|c|}{ Head Count (HC,\%) } \\
\hline $\mathrm{Q}^{\mathrm{a}}$ & 11.2 & 35.4 & 60.9 & 21.7 \\
\hline Q2 & 5.7 & 25.9 & 48.0 & 13.8 \\
\hline Q3 & 4.4 & 21.7 & 42.9 & 11.6 \\
\hline Q4 & 3.2 & 17.9 & 36.4 & 6.9 \\
\hline Total & 6.1 & 25.3 & 47.3 & 13.6 \\
\hline \multicolumn{5}{|c|}{ Mean Gap(\%) } \\
\hline Q1 & 4.8 & 31.4 & 61.2 & 15.5 \\
\hline Q2 & 3.0 & 16.1 & 41.0 & 8.8 \\
\hline Q3 & 1.3 & 12.5 & 35.9 & 5.4 \\
\hline Q4 & 1.1 & 7.2 & 12.2 & 3.1 \\
\hline Total & 2.5 & 16.8 & 38.0 & 8.3 \\
\hline \multicolumn{5}{|c|}{ Mean Positive Gap (\%) } \\
\hline Q1 & 42.9 & 88.5 & 100.5 & 71.4 \\
\hline Q2 & 52.0 & 61.9 & 85.4 & 63.8 \\
\hline Q3 & 29.5 & 57.7 & 83.7 & 46.6 \\
\hline Q4 & 34.4 & 39.8 & 33.5 & 44.9 \\
\hline Total & 41.0 & 66.5 & 80.3 & 61.1 \\
\hline
\end{tabular}

${ }^{a}$ Quartile $1(\mathrm{Q} 1)$ is the poorest and Quartile $4(\mathrm{Q} 4)$ is the richest

hypertensive patients and their households in rural Shandong, China.

In this study, the incidence of CHE is $13.6 \%$. In order to better understand the incidence of CHE, we try to compare the CHE in this study to some others in China which used the same measuring method of CHE as ours. It is higher than the reported 6.7, 11.19 and 5.4\% in general households in rural Sichuan, rural Yunnan and rural Shaanxi respectively [36-38] . A study by Zhao et al. estimated an incidence of 6.3 and $5.4 \%$ in general households in rural Gansu and Heilongjiang, which were both lower than the incidence in this study [39]. Another study conducted in the same province as this study indicated that 4.5 and $4.3 \%$ of the rural general households experienced CHE in 2006 and 2008, which were also lower than the incidence of CHE in this study [40] . Similarly, the incidence of impoverishment in the current study is $10.8 \%$, which is higher than the $7.0 \%$ found in a study using the National Health Survey data in 2008 and $2.6 \%$ in another study using the 2000 Chinese National Bureau of Statistics data [23, 41]. Even though the incidence of CHE in this study is lower the reported $23.48 \%$ in hypertensive patients' households in rural Shaanxi in 2013 [42], the results both from Shandong and Shaanxi indicate that hypertension might exert a significant effect to incur $\mathrm{CHE}$ and poverty on the patients and their households in rural China. In addition, the Chinese government has taken several measures to promote essential public health service (including hypertension case management) and also universal health coverage in the past 5 years. The gap in CHE among hypertensive patients between Shandong and Shaanxi province, might imply a progress in such measures.

Not surprisingly, the results of this study reveal that the hypertensive patients with complication are more likely to experience CHE compared with those without complication. In addition, with the increase in the types of hypertensive complications, the intensity and incidence of CHE also increase significantly. Some previous studies indicate that the treatment and healthcare costs for hypertensive complications (i.e., coronary heart disease, stroke) are particularly expensive [40] .The high economic burden for hypertension patients and their households mainly comes from hypertensive complications [43] . This finding implies a need for the community health providers to monitor the blood pressure regularly for the rural hypertensive patients, so as to prevent the progression of the hypertension and the occurrence of its complications. The primary goal of health insurance scheme is to prevent patients from falling into poverty trap due to healthcare expenditures worldwide. However, in this study, we found that health insurance has no significant effect on the prevention of $\mathrm{CHE}$, which is similar with some previous studies [44-47]. This finding indicates that the healthcare expenditure for hypertension after reimbursement still poses a high 
Table 4 Relationship between patient's characteristics and incidence of catastrophic health expenditure in rural Shandong, China, 2016

\begin{tabular}{|c|c|c|c|c|c|c|c|c|c|}
\hline \multirow[t]{2}{*}{ Variable } & \multicolumn{3}{|c|}{ One complication } & \multicolumn{3}{|c|}{ Two or more complications } & \multicolumn{3}{|c|}{ No complication } \\
\hline & N (\%) & $x^{2}$ & $P$ & $\mathrm{~N}(\%)$ & $x^{2}$ & $P$ & N (\%) & $x^{2}$ & $P$ \\
\hline Age (years) & & 8.66 & 0.034 & & 4.85 & 0.089 & & 25.91 & 0.000 \\
\hline$\leq 45$ & $10(1.0)$ & & & $0(0.0)$ & & & $50(2.5)$ & & \\
\hline $46-60$ & $218(21.5)$ & & & $10(11.0)$ & & & $559(27.8)$ & & \\
\hline $61-70$ & $478(47.2)$ & & & $48(52.7)$ & & & $812(40.4)$ & & \\
\hline$>70$ & $303(30.3)$ & & & $33(36.3)$ & & & $588(29.3)$ & & \\
\hline Sex & & 1.10 & 0.294 & & 7.97 & 0.005 & & 1.87 & 0.172 \\
\hline Male & $337(33.3)$ & & & $35(38.5)$ & & & $770(38.3)$ & & \\
\hline Female & $676(66.7)$ & & & $56(61.5)$ & & & $1239(61.7)$ & & \\
\hline Marital status & & 15.11 & 0.001 & & 0.00 & 0.991 & & 57.73 & 0.000 \\
\hline Single & $12(1.2)$ & & & $0(0.0)$ & & & $52(2.6)$ & & \\
\hline Married & $828(81.7)$ & & & $72(79.1)$ & & & $1671(83.2)$ & & \\
\hline Bereft of spouse ${ }^{a}$ & $173(17.1)$ & & & $19(20.9)$ & & & $286(14.2)$ & & \\
\hline Education & & 1.41 & 0.703 & & 9.17 & 0.027 & & 21.13 & 0.000 \\
\hline None & $528(52.1)$ & & & $47(51.6)$ & & & $816(40.6)$ & & \\
\hline Primary school & $314(31.0)$ & & & $25(27.5)$ & & & $718(35.7)$ & & \\
\hline Junior school & $134(13.2)$ & & & $13(14.3)$ & & & $370(18.4)$ & & \\
\hline Senior school or above & $37(3.7)$ & & & $6(6.6)$ & & & $105(5.2)$ & & \\
\hline Household income & & 23.05 & 0.000 & & 2.93 & 0.403 & & 32.33 & 0.000 \\
\hline $\mathrm{Q} 1^{\mathrm{b}}$ & $279(27.5)$ & & & $35(38.5)$ & & & $469(23.3)$ & & \\
\hline Q2 & $270(26.7)$ & & & $23(25.3)$ & & & $481(23.9)$ & & \\
\hline Q3 & $260(25.7)$ & & & $18(19.8)$ & & & $523(26.0)$ & & \\
\hline Q4 & $204(20.1)$ & & & $15(16.5)$ & & & $536(26.7)$ & & \\
\hline Health insurance ${ }^{c}$ & & 3.38 & 0.337 & & 2.25 & 0.522 & & 3.72 & 0.294 \\
\hline URBMI & $970(95.8)$ & & & $86(94.5)$ & & & 1927 (95.9) & & \\
\hline UEBMI & $13(1.3)$ & & & $1(1.1)$ & & & $26(1.3)$ & & \\
\hline $\mathrm{CMI}$ & $3(0.3)$ & & & $1(1.1)$ & & & $7(0.3)$ & & \\
\hline Others $^{d}$ & $27(2.7)$ & & & $3(3.1)$ & & & $49(2.4)$ & & \\
\hline Duration of disease & & 1.67 & 0.645 & & 0.89 & 0.828 & & 1.74 & 0.629 \\
\hline$\leq 5$ & $255(25.2)$ & & & $14(15.4)$ & & & $762(37.9)$ & & \\
\hline $6-10$ & $319(31.5)$ & & & $32(35.2)$ & & & $699(34.8)$ & & \\
\hline $11-15$ & $171(16.9)$ & & & $16(17.6)$ & & & $210(10.5)$ & & \\
\hline$>15$ & $268(26.5)$ & & & 29 (31.9) & & & $338(16.8)$ & & \\
\hline In-Patient & & 192.49 & 0.000 & & 33.58 & 0.000 & & 219.11 & 0.000 \\
\hline No & $287(28.3)$ & & & $44(48.4)$ & & & 1929 (95.6) & & \\
\hline Yes & $726(71.7)$ & & & $47(51.6)$ & & & $80(4.0)$ & & \\
\hline Out-Patient & & 10.06 & 0.002 & & 8.03 & 0.005 & & 55.49 & 0.000 \\
\hline No & $200(19.7)$ & & & $62(68.1)$ & & & 1829 (91.0) & & \\
\hline Yes & $813(80.3)$ & & & 29 (31.9) & & & $181(9.0)$ & & \\
\hline Dibao $^{e}$ & & 18.33 & 0.000 & & 0.01 & 0.932 & & 0.04 & 0.839 \\
\hline No & $68(6.7)$ & & & 78 (85.7) & & & 1920 (95.6) & & \\
\hline Yes & 945 (93.3) & & & $13(14.3)$ & & & $89(4.4)$ & & \\
\hline
\end{tabular}


Table 4 Relationship between patient's characteristics and incidence of catastrophic health expenditure in rural Shandong, China, 2016 (Continued)

\begin{tabular}{|c|c|c|c|c|c|c|c|c|c|}
\hline \multirow[t]{2}{*}{ Variable } & \multicolumn{3}{|c|}{ One complication } & \multicolumn{3}{|c|}{ Two or more complications } & \multicolumn{3}{|c|}{ No complication } \\
\hline & $\mathrm{N}(\%)$ & $x^{2}$ & $P$ & $\mathrm{~N}(\%)$ & $x^{2}$ & $P$ & $\mathrm{~N}(\%)$ & $x^{2}$ & $P$ \\
\hline Be in debt & & 0.24 & 0.627 & & 3.49 & 0.062 & & 7.60 & 0.006 \\
\hline No & $145(14.3)$ & & & $68(74.7)$ & & & $1771(88.2)$ & & \\
\hline Yes & $868(85.7)$ & & & $23(25.3)$ & & & $238(11.8)$ & & \\
\hline Head of household & & 5.93 & 0.015 & & 0.53 & 0.466 & & 8.36 & 0.004 \\
\hline No & $523(51.6)$ & & & $45(49.5)$ & & & $889(44.3)$ & & \\
\hline Yes & $490(48.4)$ & & & $46(50.5)$ & & & $1120(55.7)$ & & \\
\hline Head of household's gender & & 1.23 & 0.268 & & 2.44 & 0.118 & & 30.93 & 0.000 \\
\hline Male & $766(75.6)$ & & & $72(79.1)$ & & & $432(21.5)$ & & \\
\hline Female & $247(24.4)$ & & & $19(20.9)$ & & & $1577(78.5)$ & & \\
\hline Family size & & 15.23 & 0.000 & & 3.31 & 0.069 & & 0.16 & 0.694 \\
\hline$\leq 4$ & $931(91.9)$ & & & $84(92.3)$ & & & $1843(91.7)$ & & \\
\hline$>4$ & $82(8.1)$ & & & $7(7.7)$ & & & $166(8.3)$ & & \\
\hline Living arrangements & & 10.93 & 0.000 & & 1.74 & 0.42 & & 79.09 & 0.000 \\
\hline Empty-nest single & $156(15.4)$ & & & $15(16.5)$ & & & $269(13.4)$ & & \\
\hline Empty-nest couple & $670(66.1)$ & & & $63(69.2)$ & & & $1298(64.6)$ & & \\
\hline Others & $187(18.5)$ & & & $13(14.3)$ & & & $442(22.0)$ & & \\
\hline
\end{tabular}

The $P$-values indicate statistical significance at $5 \%$ level

a 8 divorced participants are categorized into the group "Bereft of spouse"

${ }^{b}$ Quartile $1(\mathrm{Q} 1)$ is the poorest and Quartile $4(\mathrm{Q} 4)$ is the richest

c URBMI Urban Residents Basic Medical Insurance, UEBMI Urban Employees Basic Medical Insurance, CMI Commercial Medical Insurance

d 40 uninsured patients are categorized into the group "others";

e "Dibao" means low-income households in China, which living and medical aids from municipal governments and other welfare programs

financial burden on the patients' households. In other words, the protection effect of the health insurance scheme on the hypertension and its complications is very limited. Therefore, to upgrade the height of coverage of the health insurance schemes targeting the hypertensive patients, especially for those patients with complications, is essential to decrease the possibility of $\mathrm{CHE}$ in the hypertensive patients' households. A previous study on Global Budget Payment System (GBPS) has shown that it can help reduce total medical expense, and OOP expenditure significantly. Therefore, to explore new targeting medical insurance payment system is also important to reduce the incidence of CHE on hypertension and its complications [48].

Similarly, our results find that the outpatient and hospitalization service use are the determinants of CHE in hypertensive patients $[23,49]$. A study in Yichang, China found that average expense for each hypertension-related outpatient and inpatient visit was US\$ 36.1 and US\$ 1877.0 respectively [50]. Hypertensive patients need to use outpatient visit for about eight times per year [51] . The health service utilization posed a high direct economic burden on the patients and their households. This was also demonstrated to be true in some other countries $[52,53]$. In addition, some other indirect costs, such as transportation and accommodation expenses for health service use, and formal care expenses for those need care, also bring dramatic burden to the patients and their households. This finding suggests for the policy makers to develop interventions of healthcare cost control, especially for those inpatient services, to reduce healthcare expenditure for the hypertensive patients and their households. For example, to improve the two-way referral system and its supporting measures would probably reduce total healthcare expenditure in inpatient and outpatient use among the hypertensive patients [54]. Simultaneously, practitioners in community health centers should carry out hypertensive patients targeting health education, especially in patients with poor education, to improve their understanding of hypertension and its consequences so as to prevent the progression of the hypertension and its complications.

Consistent with the studies in some other diseases, this study also reveals that the incidence and intensity of CHE among hypertensive patients is negatively correlated with the economic status, patients in lower income quartiles are at higher risk of experiencing CHE. In the same income quartile, the incidence and intensity of CHE increased with the increase in the number of hypertension complications. China began to implement a strategy of Targeted-Poverty-Alleviation in 2014, and the disease-caused poverty is the most common target in this strategy. This finding is meaningful to develop anti-poverty policy of pro-patients with chronic diseases 
Table 5 Logistic regression model of determinants of CHE for health care of different kinds of complications among hypertensive patients in rural Shandong, China, 2016

\begin{tabular}{|c|c|c|c|c|c|c|c|c|c|}
\hline \multirow[t]{2}{*}{ Variables } & \multicolumn{3}{|c|}{ One complication } & \multicolumn{3}{|c|}{ Two or more complications } & \multicolumn{3}{|c|}{ No complication } \\
\hline & $\mathrm{OR}$ & $95 \% \mathrm{Cl}$ & $P$ & $\mathrm{OR}$ & $95 \% \mathrm{Cl}$ & $P$ & $\mathrm{OR}$ & $95 \% \mathrm{Cl}$ & $P$ \\
\hline Household income & & & & & & $N A^{a}$ & & & NA \\
\hline Q4 & 1.0 & & & & & & & & \\
\hline $\mathrm{Q} 1^{\mathrm{b}}$ & 2.18 & $1.25-3.78$ & 0.006 & & & & & & \\
\hline Q2 & 1.39 & $0.81-2.41$ & 0.228 & & & & & & \\
\hline Q3 & 1.06 & $0.62-1.81$ & 0.839 & & & & & & \\
\hline \multicolumn{10}{|l|}{ In-Patient } \\
\hline No & 1.0 & & & 1.0 & & & 1.0 & & \\
\hline Yes & 9.14 & $6.49-12.89$ & 0.000 & 40.96 & $7.72-217.30$ & 0.000 & 20.10 & $11.47-35.33$ & 0.000 \\
\hline \multicolumn{10}{|l|}{ Out-Patient } \\
\hline No & 1.0 & & & 1.0 & & & 1.0 & & \\
\hline Yes & 1.69 & $1.13-2.53$ & 0.011 & 8.44 & $1.16-61.43$ & 0.035 & 5.62 & $3.39-9.32$ & 0.000 \\
\hline Dibao $^{c}$ & & & & & & NA & & & NA \\
\hline No & 1.0 & & & & & & & & \\
\hline Yes & 2.52 & $1.39-4.55$ & 0.002 & & & & & & \\
\hline Education & & & NA & & & NA & & & \\
\hline None & & & & & & & 1.0 & & \\
\hline Primary school & & & & & & & 0.50 & $0.31-0.82$ & 0.005 \\
\hline Junior school & & & & & & & 0.39 & $0.18-0.86$ & 0.019 \\
\hline Senior school or above & & & & & & & 0.69 & $0.24-1.98$ & 0.482 \\
\hline Living arrangements & & & NA & & & NA & & & \\
\hline Others & & & & & & & 1.0 & & \\
\hline Empty-nest single & & & & & & & 5.88 & $1.48-23.39$ & 0.012 \\
\hline Empty-nest couple & & & & & & & 1.82 & $0.61-5.38$ & 0.284 \\
\hline Observations & 1013 & & & 91 & & 2009 & & & \\
\hline Adjusted $R^{2}$ & 0.32 & & & 0.61 & & 0.28 & & & \\
\hline
\end{tabular}

The $P$ - values indicate statistical significance at $5 \%$ level

${ }^{a}$ not applicable

${ }^{b}$ Quartile $1(\mathrm{Q} 1)$ is the poorest and Quartile $4(\mathrm{Q} 4)$ is the richest

c "Dibao" means low-income households in China, which living and medical aids from municipal governments and other welfare programs

(e.g., hypertension), especially for those with complications, so as to effectively achieve the goal of the Targeted-Poverty-Alleviation strategy.

Several limitations are involved in this study. First, the number of patients with two or more complications is only $91(3.0 \%)$. Of the participants, $63.3 \%$ were women. These might result in possible bias. Second, when we collect the expenditure and income of the patient's household (such as OOP, food expenditure), even though we have tried to, it is hard to exclude recall bias.

\section{Conclusion}

This study reveals that the incidence and intensity of CHE are relatively high in hypertensive patients in rural China. Patients with complications are at higher risk of experiencing CHE than those with no complications. Our findings also show that patients who use outpatient or inpatient services are more likely to suffer from CHE. In addition, some other at-risk factors, including living arrangements, family size and education level, are also identified in some subgroups. The results imply a need of regular monitoring for blood pressure in rural hypertensive patients. Some measures to enhance adherence to anti-hypertension treatment as well as lifestyle changes to lower BP (blood pressure), are also of significance to prevent the progression of the hypertension and its complications, so as to reduce the risk of potential CHE.

\footnotetext{
Abbreviations

CHE: Catastrophic health expenditure; WHO: World health organization; OOP: Out-of-pocket; GDP: Gross Domestic Product; SBP: Systolic blood pressure; DBP: Diastolic blood pressure
}

\section{Acknowledgements}

We thank the officials of local health agencies and all participants and staff at the study sites for their cooperation. 


\section{Authors' contributions}

$\mathrm{CZ}, \mathrm{XZ}$, and $\mathrm{QX}$ conceived the idea. CZ, XZ, XG, ZJ, QX, LS, and JL participated in the statistical analysis and interpretation of the results. $X Z$ and QX drafted the manuscript. CZ gave many valuable comments on the draft and also polished it. All authors read and approved the final manuscript.

\section{Funding}

We are grateful for funding support from the National Science Foundation of China (71774104, 71473152 and 71974117), Chinese Medical Board (CMB-16257), Cheeloo Youth Scholar Grant, and Shandong University (IFYT1810, 2012DX006). The funding bodies have no role in the design of the study and collection, analysis, and interpretation of data and in writing the manuscript.

\section{Availability of data and materials}

The datasets used and/or analyzed during the current study are available from the corresponding author on reasonable request.

\section{Ethics approval and consent to participate}

The study protocol was approved by The Ethical Committee of Shandong University School of Public Health. The investigation was performed after the acquisition of written informed consents of all participants.

\section{Consent for publication}

Not applicable.

\section{Competing interests}

The authors declare there are no competing interests.

\section{Author details}

${ }^{1}$ School of Public Health, Shandong University, Jinan 250012, China. ${ }^{2}$ Shandong Center for Disease Control and Prevention, Jinan 250014, China. ${ }^{3} \mathrm{NHC}$ Key Lab of Health Econonics and Policy Research, Shandong University, Jinan 250012, China.

Received: 6 September 2019 Accepted: 6 April 2020

Published online: 22 April 2020

\section{References}

1. GBD 2013 Mortality and Causes of Death Collaborators. Global, regional, and national age-sex specific all-cause and cause-specific mortality for 240 causes of death, 1990-2013: a systematic analysis for the Global Burden of Disease Study 2013. Lancet. 2015;385:117-71.

2. Zu P. Study on economic burden and death loss of hypertension in Shanghai [D]. Shanghai: Fudan University; 2010. (in Chinese).

3. Whitworth JA. World health organization $(\mathrm{WHO}) /$ International Society of Hypertension (ISH) statement on management of hypertension. J Hypertens. 2003;21:1983-92.

4. World Health Organization. A Global Brief on Hypertension. Geneva: World Health Organization; 2013.

5. Li L. Economic burden of hypertension in Shandong province and the effect of medical insurance [D]. Jinan: Shandong University; 2013. (in Chinese).

6. Lim SS, Vos T, Flaxman AD, et al. A comparative risk assessment of burden of disease and injury attributable to 67 risk factors and risk factor clusters in 21 regions, 1990-2010: a systematic analysis for the global burden of disease study 2010. Lancet. 2012;380(9859):2224-60.

7. 2015 report on Chinese resident's chronic disease and nutrition [M]. Beijing: People's Medical Publishing House, 2015.

8. Guidelines for Prevention and Treatment of Hypertension in China 2018 Revised edition [J]. Cardiovascular and Cerebrovascular Disease Prevention and Treatment, 2019, 19 (1): 1-44.

9. Razola VE, Gutierrez L, Bloomfield G, et al. Hypertension prevalence, awareness, treatment, and control in selected LMIC communities[J]. Glob Heart. 2016;11(1):47-59.

10. Li $Y$, Yang $L$, Wang $L$, et al. Burden of hypertension in China: A nationally representative survey of 174,621 adults [J]. Int J Cardiol. 2017;227:516-23.

11. Sui H, Wei C, Wang W. Interpretation of Report on Cardiovascular Diseases in China (2015) [J]. Chin J Cardiovasc Med C. 2016;21(4):2592619 (in Chinese)
12. Chen HZ, Guo B, Dai H, et al. Study on change of out-of-pocket health payment in Heilongjiang Province during 2004-2014. Chinese J Soc Med. 2018;35(05):539-42 (in Chinese).

13. Atella $\mathrm{V}$, Brugiavini A, Pace $\mathrm{N}$. The health care system reform in China: effects on out-of-pocket expenses and saving[J]. China Econ Rev. 2015;34: 182-95.

14. Meng Q, Xu L, Zhang Y, et al. Trends in access to health services and financial protection in China between 2003 and 2011: a cross-sectional study. Lancet. 2012;379:805-14.

15. Li X. Study on the status of chronic disease and risk factors of rural residents in Shandong province [D]. Jinan: Shandong University; 2015. (in Chinese).

16. Sun $Y$, Yan $Y$, Xue Q, et al. Diabetes-related household catastrophic healthcare expenditure and its income-related inequality in Shaanxi province: a decomposition analysis. Chin J Public Health. 2018;34(8):1143-7 (in Chinese).

17. Fang $H$, Zhao $Y$, Wang J, et al. A study on financial equity: analysis on household health expenditure on catastrophic diseases. Chin Health Econ. 2003;22:5-7 (in Chinese).

18. Cui Y, Liu JA, Wang Q, et al. Analysis of catastrophic health payment among rural families with hypertension patients in poor region. Chinese Primary Health Care. 2011;25:37-9 (in Chinese).

19. World Health Organization. the World Health Report 2000, Health Systems: Improving Performance. Geneva: WHO; 2000.

20. Hajizadeh M, Nghiem HS. Out-of-pocket expenditures for hospital care in Iran: who is at risk of incurring catastrophic payments? Int J Health Care Finance Econ. 2011;11(4):267-85.

21. Xu K, Distribution of Health Payments and Catastrophic Spending. Methodology. Ginebra: World Health Organization - Discussion paper N²; 2005.

22. Wagstaff A, Van Doorslaer E. Catastrophic and impoverishment in paying for health care: with application to Vietnam 1993-98. Health Econ. 2003;12:92134.

23. Li $Y, W u Q, X u L$, et al. Factors affecting catastrophic health expenditure and impoverishment from medical expenses in China: policy implications of universal health insurance. Bull World Health Organ. 2012;90:664-71.

24. Azzani M, Roslani AC, Su TT. Determinants of household catastrophic health expenditure: a systematic review. Malays J Med Sci. 2019;26(1):15-43.

25. Lu ZL, Tang JL, Zhang GH, et al. Prevalence, awareness, treatment and control of hypertension in adults in Shandong province, 2013[J]. Chinese J Epidemiol. 2016;37(9):1207-12 (in Chinese).

26. Jing Z, Chu J, Imam Syeda Z, et al. Catastrophic health expenditure among type 2 diabetes mellitus patients: a province-wide studyin Shandong, China. J Diabetes Investig. 2018. https://doi.org/10.1111/jdi.12901.321.

27. Guidelines for prevention and treatment of hypertension in China ( revised version 2010). See http://www.360doc.com/content/16/0320/08/2 00041_543731387.shtml. Accessed 20 Mar 2020, in Chinese.

28. Ge D, Zhang X, Guo X, Chu J, Sun L, Zhou C. Suicidal ideation among the hypertensive individuals in Shandong, China: A Path Analysis. BMC Psychiatry. 2019;19(1):266.

29. O'Donnell O, van Doorslaer E, Wagstaff A, et al. Analyzing health equity using household survey data: a guide to techniques and their implementation. Washington, DC: World Bank Group; 2007. p. 1.

30. Su TT, Kouyaté B, Flessa S. Catastrophic household expenditure for health care in a low income society: a study from Nouna District, Burkina Faso. Bull World Health Organ. 2006;84(1):21-7.

31. Chuma J, Maina T. Catastrophic health care spending and impoverishment in Kenya. BMC Health Serv Res. 2012;12:413.

32. World Bank. World development indicators, out of pocket health expenditure (as a percentage of total health expenditure). 2013. http://data. worldbank.org/indicator/SH.XPD.OOPC.TO.ZS. Accessed 4 July 2019.

33. Yan J, Yan YL, et al. Empirical study on the impact of health expenditure on poverty under new rural cooperative medical scheme. Chinese Health Econ. 2012;31(6):37-9 (in Chinese).

34. Yang T, Chu J, Zhou C, et al. Catastrophic health expenditure: a comparative analysis of empty-nest and on-empty-nest households with seniors in Shandong, China. BMJ Open. 2016;6:e010992.

35. Zhou C, Long Q, Chen J, et al. Factors that determine catastrophic expenditure for tuberculosis care: a patient survey in China. Infect Dis Poverty. 2016;5(1):6.

36. Zhou Y, Tang Y, Zhang Q, et al. Catastrophic health expenditure before and after reimbursement from the new rural cooperative medical scheme in 
rural Zigong, Sichuan province. J Sichuan University (Medical Science Edition). 2016;47(5):768-71 (in Chinese).

37. Yin J, Zhao H, Wang $Y$, et al. Influencing factors of catastrophic health expenditure in rural households in Weishan county, Yunnan province. Soft Sci Health. 2014;28(4):205-7 (in Chinese).

38. Yan J, Hao N, Liao S, et al. The changes and influencing factors on catastrophic health expenditures before and after new health care reform: a study in Mei County, Shaanxi province. Chinese J Health Policy. 2013;6(2): 30-3 (in Chinese) OA.

39. Zhao Y, Tao S, Wan Q, et al. Case study on catastrophic health expenditure in rural China. Chinese Health Econ. 2004;23(4):5-8 (in Chinese).

40. Gong X, Yu R, Meng Q, et al. Study on the effect of new rural cooperative medical system on catastrophic health care payment. Res Health Econ. 2009;9:27-9 (in Chinese).

41. van Doorslaer E, O'Donnell O, Rannan-Eliya RP, et al. Effect of payments for health care on poverty estimates in 11 countries in Asia: an analysis of household survey data. Lancet. 2006;368(9544):1357-64.

42. Si Y, Zhou Z, Su M, et al. Catastrophic healthcare expenditure and its inequality for households with hypertension: evidence from the rural areas of Shaanxi Province in China. Int J Equity Health. 2017;16:27.

43. Zhai $Y, \mathrm{Hu} J$, Kong $\mathrm{L}$, et al. Study on the economic burden of coronary heart disease and stroke caused by hypertension in Chinese residents [J]. Chinese J Epidemiol. 2006;27(9):744-7 (in Chinese)

44. Jiang C, Ma J, Zhang X, et al. Measuring financial protection for health in families with chronic conditions in rural China. BMC Public Health. 2012;12: 988. https://doi.org/10.1186/1471-2458-12-988.

45. Liu H, Zhao Z. Impact of China's urban resident basic medical insurance on health care utilization and expenditure. IZA Discussion Paper No. 6768 Bonn: Institute for the Study of Labor, University of Bonn; 2012.

46. Wagstaff $\mathrm{A}$, Lindelow $\mathrm{M}$, Gao J, et al. Extending health insurance to the rural population: an impact evaluation of China's new cooperative medical scheme. J Health Econ. 2009;28:1-19.

47. Lei $X$, Lin $S$. The new cooperative medical scheme in rural China: does more coverage mean more service and better health? Health Econ. 2009;18:2546.

48. Huang $Y$, Liu Y, Yang $X$, et al. Global budget payment system helps to reduce outpatient medical expenditure of hypertension in China [J]. SpringerPlus. 2016;5(1):1877.

49. Chen R, Yin A, Zhao W, et al. Catastrophic health expenditure and its determinants among rural residents in Tengzhou City. Chinese Health Econ. 2012;31(3):19-21 (in Chinese).

50. Yang J, Xu Y, Xu C. Analysis of hypertension treatment cost based on big data in Yichang City, 2015. J Pub Health Prev Med. 2016;27(6):49-51 (in (hinese).

51. Xin Y, Rao K, Xu L. Analysis of economic burden of hypertension in rural and urban households in China. Chinese Health Econ. 2010;29(5):69-71 (in (hinese).

52. Singh JA, Yu S. Emergency department and inpatient healthcare utilization due to hypertension. BMC Health Serv Res. 2016;16:303.

53. Mutowo MP, Lorgelly PK, Laxy M, et al. The hospitalization costs of diabetes and hypertension complications in Zimbabwe: estimations and correlations. J Diabetes Res. 2016;2016:9754230.

54. Cheng MS, Qian DF, Feng ZC. Study on the Catastrophic Health Expenditure on the Patients with Hypertension in the Minority-inhabited Areas in Western China. Chinese Health Econ. 2016;35(12):73-5 (in Chinese).

\section{Publisher's Note}

Springer Nature remains neutral with regard to jurisdictional claims in published maps and institutional affiliations.

Ready to submit your research? Choose BMC and benefit from:

- fast, convenient online submission

- thorough peer review by experienced researchers in your field

- rapid publication on acceptance

- support for research data, including large and complex data types

- gold Open Access which fosters wider collaboration and increased citations

- maximum visibility for your research: over $100 \mathrm{M}$ website views per year

At $\mathrm{BMC}$, research is always in progress.

Learn more biomedcentral.com/submissions 